\title{
STRUCTURAL CHARACTERIZATION OF GLYCOPEPTIDE ANTIBIOTICS RELATED TO VANCOMYCIN BY FAST ATOM BOMBARDMENT MASS SPECTROMETRY
}

\author{
Gerald D. Roberts, Steven A. Carr*, Susan Rottschaefer \\ and Peter W. JefFs \\ Department of Analytical, Physical and Structural Chemistry, \\ Smith Kline \& French Laboratories, \\ 1500 Spring Garden Street, Philadelphia, PA 19101, U.S.A.
}

(Received for publication February 19, 1985)

\begin{abstract}
A series of glycopeptide antibiotics related to the vancomycin-ristocetin family have been successfully analyzed by fast atom bombardment mass spectrometry (FABMS). The FAB mass spectra of glycopeptides weighing up to 2,100 daltons exhibit intense molecular ions and fragment ions from which information concerning carbohydrate composition and sequence are readily obtained. Careful adjustment of the FABMS experimental conditions has enabled the accurate masses of the glycopeptides to be determined by high resolution FABMS with an accuracy of better than six ppm. Comparison of the observed molecular ion cluster pattern with calculated isotope distributions reveals the precise number of chlorine atoms in these molecules, which, together with the accurate mass data, can be used to restrict the number of possible elemental compositions to a meaningfully small value. These techniques have been used to characterize several glycopeptides of known structure including ristocetin, actinoidin, avoparcin, vancomycin and A35512B, as well as aridicins A, B and C which are three new, novel members of the vancomycin class.
\end{abstract}

Glycopeptide antibiotics related to the vancomycin-ristocetin group have been the subject of increasing attention over the past three years due to their use for the treatment of methicillin-resistant staphylococcal infections in humans and their potential as growth promotants in animal feed stocks. The developing importance of this family of compounds has increased the need for methods to enable rapid characterization of small quantities of material. We report here the use of fast atom bombardment mass spectrometry (FABMS) ${ }^{1)}$ as a valuable tool in providing key structural information at the microgram level for this class of antibiotics. The techniques developed have been used to characterize glycopeptides aridicins A, B and C isolated from a new genus of organisms, Kibdelosporangium aridum. These molecules have recently been shown to be new, novel members of the vancomycin class ${ }^{2,8)}$.

Until recently mass spectral methods were unable to provide useful data for the definition of molecular weights of intact glycopeptide antibiotics of the vancomycin-ristocetin class. Plasma desorption mass spectrometry using a ${ }^{252} \mathrm{Cf}$ source has been used to produce a response in the molecular ion region for ristocetin and other intact glycopeptide antibiotics ${ }^{3)}$. However, because the resolution achievable in such experiments is poor, the resulting molecular weights could only be defined to within $\pm 2 \sim 5$ mass units. Although some success has been reported using the FAB ionization technique with vancomycin ${ }^{4}$, the smallest known member of this family, FAB mass spectra of higher molecular weight glycopeptides in this family such as ristocetin, actinoidin, avoparcin and A35512B have not been reported to date ${ }^{3,5}$. During the preparation of this report low resolution FAB mass spectral data have been obtained on teicoplanin by two separate groups ${ }^{10,11)}$. Studies carried out in our laboratories have now shown that when an appropriate matrix is used to dissolve the sample, high quality FAB 
mass spectra may be obtained with sufficient molecular ion intensity to enable accurate masses to be determined. In addition, numerous fragment ions are observed which yield information about the carbohydrate composition, and, in some cases, sequence of the carbohydrate moieties.

\section{Experimental}

FAB mass spectra were obtained using a VG ZAB-1F-HF mass spectrometer equipped with a standard FAB source and a DS-2000 data system. The solid sample $(5 \sim 10 \mu \mathrm{g})$ was dispersed on the stainless steel probe in a matrix of monothioglycerol (3-mercapto-1,2-propanediol), or monothioglycerol/glycerol containing oxalic acid, acetic acid or trifluoroacetic acid. Glycerol alone was not suitable as the liquid matrix. The accelerating voltage of the mass spectrometer was maintained at $8 \mathrm{kV}$ while $8 \mathrm{keV}$ xenon atoms at a discharge current of $1 \mathrm{~mA}$ were used to bombard the sample. Spectra were recorded on oscillograph paper using a linear downscan from $\mathrm{m} / \mathrm{z} 2,200$ at a rate of 20 seconds/decade.

Ristocetin and vancomycin were obtained from Sigma Chemical Co. Actinoidins A and B, avopar-

Table 1. Glycopeptide antibiotics examined by FABMS.

\begin{tabular}{llc}
\hline Glycopeptide & $\begin{array}{c}\text { Nominal molecular } \\
\text { weight by FABMS }\end{array}$ \\
\hline $\mathbf{1}$ & Vancomycin & 1,447 \\
$\mathbf{2}$ & Ristocetin A & 2,066 \\
$\mathbf{3}$ & Actinoidin A & 1,759 \\
$\mathbf{4}$ & Actinoidin B & 1,793 \\
$\mathbf{5}$ & Avoparcin & 1,941 \\
$\mathbf{6}$ & A35512B & 1,952 \\
$\mathbf{7}$ & Aridicin A & 1,786 \\
$\mathbf{8}$ & Aridicin B & 1,800 \\
$\mathbf{9}$ & Aridicin C & 1,814 \\
\hline
\end{tabular}

cin and A35512 were generously supplied by the USSR Academy of Medical Science, American Cyanamid Co., and Lilly Research Labs., respectively.

\section{Results and Discussion}

Our initial efforts were directed toward finding suitable conditions for the FABMS analysis of previously well characterized glycopeptide antibiotics $^{6,7)}$ (compounds 1 6, Table 1). Samples dissolved in a matrix of monothioglycerol or monothioglycerol/glycerol containing acid

Fig. 1. Structure of ristocetin A.

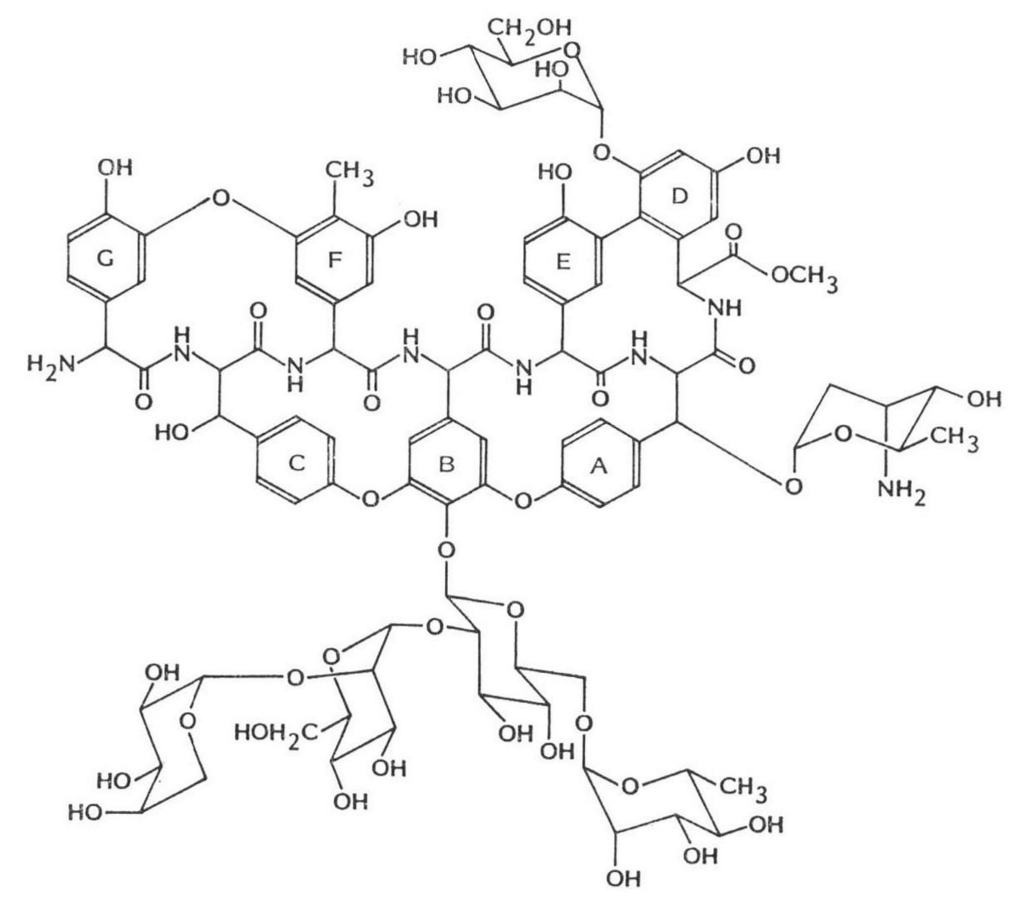


Fig. 2. FAB mass spectrum of ristocetin $\mathrm{A} ; 10 \mu \mathrm{g}$ in monothioglycerol and acetic acid.
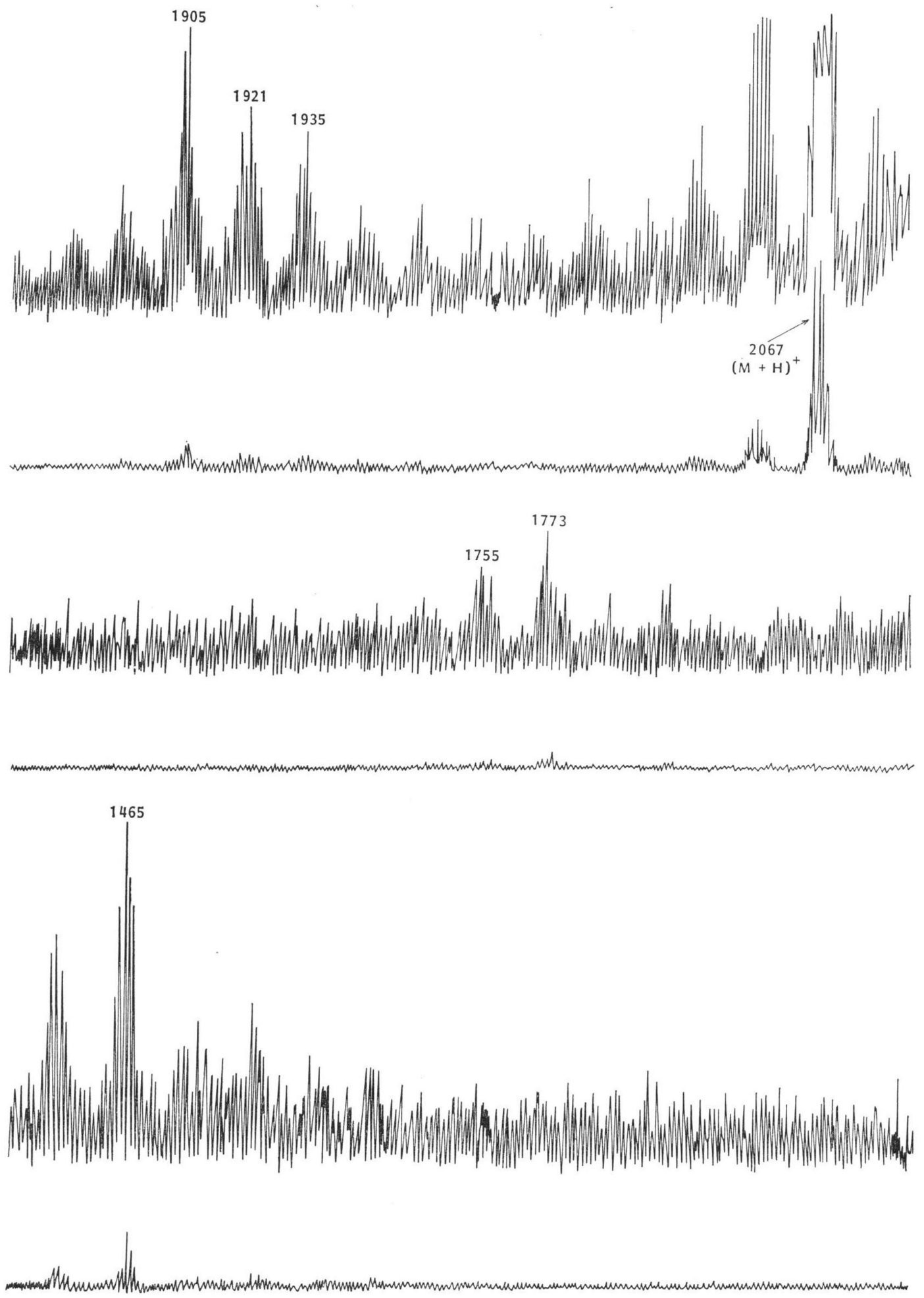
Table 2. Carbohydrate content of the glycopeptide antibiotics.

\begin{tabular}{|c|c|c|}
\hline Antibiotic & $\begin{array}{c}\text { Carbohydrates } \\
\text { known to be present }\end{array}$ & $\begin{array}{c}\text { Carbohydrates } \\
\text { indicated by FABMS }\end{array}$ \\
\hline Vancomycin & Glucose, vancosamine & Hexose, vancosamine \\
\hline Ristocetin A & $\begin{array}{l}\text { Glucose, } 2 \text { mannose, rhamnose, } \\
\text { arabinose, ristosamine }\end{array}$ & $\begin{array}{l}2 \text { Hexose (one terminal, one internal), } \\
\text { rhamnose, arabinose, }\end{array}$ \\
\hline Actinoidin A & $\begin{array}{l}\text { Glucose, mannose, } \\
\text { actinosamine, acosamine }\end{array}$ & $\begin{array}{l}2 \text { Hexose (one terminal, one internal), } \\
\text { actinosamine (terminal), } \\
\text { acosamine (terminal) }\end{array}$ \\
\hline Actinoidin B & $\begin{array}{l}\text { Glucose, mannose, } \\
\text { actinosamine, acosamine }\end{array}$ & $\begin{array}{l}2 \text { Hexose (one terminal, one internal), } \\
\text { actinosamine (terminal), } \\
\text { acosamine (terminal) }\end{array}$ \\
\hline Avoparcin & $\begin{array}{l}\text { Glucose, mannose, rhamnose, } \\
2 \text { ristosamine }\end{array}$ & Hexose, rhamnose, ristosamine \\
\hline A35512B & $\begin{array}{l}\text { Glucose, mannose, fucose, } \\
\text { rhamnose, vancosamine }\end{array}$ & $\begin{array}{l}2 \text { Hexose (one terminal, one internal), } \\
\text { fucose and/or rhamnose }\end{array}$ \\
\hline Aridicin A & $\begin{array}{l}\text { Mannose, } 2 \text { deoxy-2-(alkylamido)- } \\
\left.\text { D-glucuronic acid (alkyl }=\mathrm{C}_{\vartheta} \mathrm{H}_{12}\right)\end{array}$ & $\begin{array}{l}\text { Mannose (terminal), } 2 \text { deoxy-2-(alkylamido)- } \\
\text { D-glucuronic acid (terminal) (alkyl }=\mathrm{C}_{\vartheta} \mathrm{H}_{18} \text { ) }\end{array}$ \\
\hline Aridicin B & $\begin{array}{l}\text { Mannose, } 2 \text { deoxy-2-(alkylamido)- } \\
\left.\text { D-glucuronic acid (alkyl }=\mathrm{C}_{10} \mathrm{H}_{21}\right)\end{array}$ & $\begin{array}{l}\text { Mannose (terminal), } 2 \text { deoxy-2-(alkylamido)- } \\
\left.\text { D-glucuronic acid (terminal) (alkyl }=\mathrm{C}_{10} \mathrm{H}_{21}\right)\end{array}$ \\
\hline Aridicin C & $\begin{array}{l}\text { Mannose, } 2 \text { deoxy-2-(alkylamido)- } \\
\left.\text { D-glucuronic acid (alkyl }=\mathrm{C}_{11} \mathrm{H}_{23}\right)\end{array}$ & $\begin{array}{l}\text { Mannose (terminal), } 2 \text { deoxy-2-(alkylamido)- } \\
\left.\text { D-glucuronic acid (terminal) (alkyl }=\mathrm{C}_{11} \mathrm{H}_{23}\right)\end{array}$ \\
\hline
\end{tabular}

(acetic, oxalic or trifluoroacetic) produced the most intense and reproducible mass spectra. Using these optimal matrices FAB mass spectra exhibiting intense molecular weight-related ions $\left((M+H)^{+}\right.$ and $\left.(\mathrm{M}+\mathrm{Na})^{+}\right)$and fragments reflecting carbohydrate composition were obtained for all of the antibiotics listed in Table 1, including the three major components of the aridicin antibiotic complex.

The results obtained for ristocetin A (Fig. 1), the largest and most complex member of this family, are typical of the FAB mass spectra of these glycopeptides (Fig. 2). An intense $(M+H)^{+}$ion is present at $m / z$ 2,067 which establishes the molecular weight of the intact molecule. The carbohydrate composition may be readily confirmed by the difference between the mass spectrometrically determined molecular weight of the glycopeptide and the corresponding aglycone (i.e., 2,066-1,173=893) which is obtained from the parent glycopeptide under suitable hydrolysis conditions. With the exception of the hexoses, mannose and glucose, each of the carbohydrate constituents contributes a unique mass increment, $i$, to the weight of the intact molecule (i.e., $i_{\text {mannose }}=i_{\text {glucose }}=162, i_{\text {arabinose }}=132, i_{\text {rhamnose }}=146$ and $\left.i_{\text {ristosamine }}=129\right)$. The observed mass difference, corresponding to a composition of one residue each of arabinose, rhamnose and ristosamine and three hexoses (glucose and mannose), is consistent with the results obtained by chemical composition analysis (Table 2). As noted above, the FAB mass spectra do not allow isobars such as rhamnose and fucose $(i=146)$ to be distinguished. Conventional chemical, chromatographic and MS techniques must be used to identify the specific isomers present.

The carbohydrate composition is further characterized by specific fragment ions observed in the FAB mass spectra ${ }^{7}$. Cleavage between the anomeric carbon and glycosidic oxygen is accompanied by hydrogen transfer to form a new glycopeptide with one (or more) fewer sugar residues than the parent molecule. In the case of ristocetin, these fragments are observed (following protonation) at $m / z 1,935$, 1,921 and 1,905 (Fig. 2) which correspond to the loss of arabinose, rhamnose and hexose (glucose or mannose), respectively. All of these sugar residues must be located at terminal locations in order to readily observe their loss directly from the $(\mathrm{M}+\mathrm{H})^{+}$. In addition, the abundant fragment at $\mathrm{m} / \mathrm{z}$ 
Fig. 3. Structural components of aridicin A.

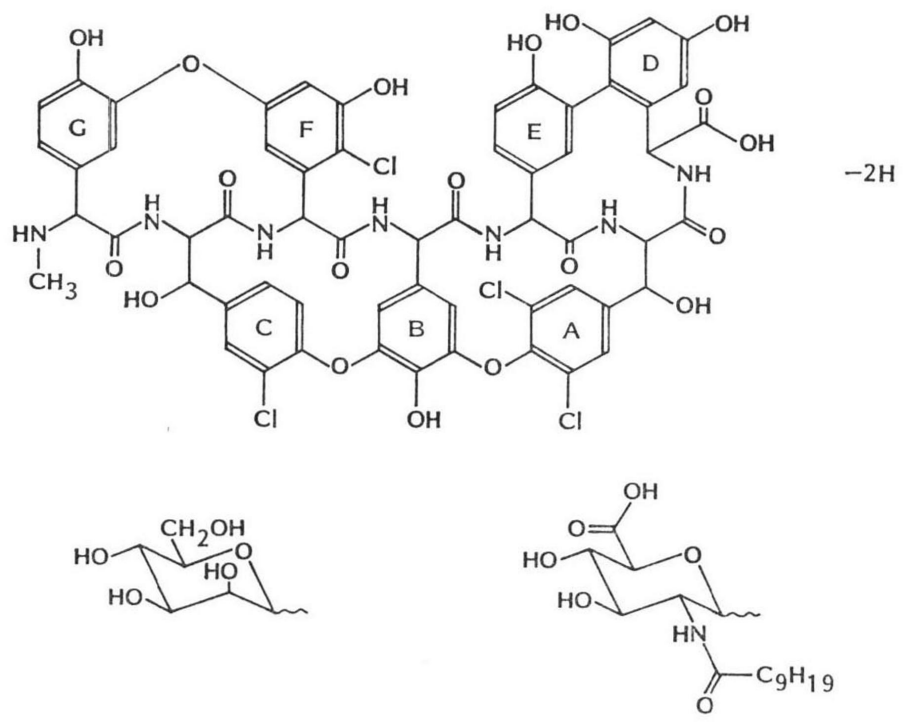

Table 3. Accurate mass determinations of the aridicins.

\begin{tabular}{lccc}
\hline \multirow{2}{*}{ Compound } & \multicolumn{2}{c}{ Mass $(\mathrm{M}+\mathrm{H})^{+}$} & $\mathrm{MH}_{\text {calcd }}-\mathrm{MH}_{\text {measured }}$ \\
\cline { 2 - 3 } & Calcd & Measured & 0.005 \\
\hline Aglycone of aridicin A & $1,296.160$ & $1,296.155$ & 0.003 \\
Aridicin A & $1,787.397$ & $1,787.394$ & 0.004 \\
Aridicin B & $1,801.413$ & $1,801.409$ & 0.005 \\
Aridicin C & $1,815.428$ & $1,815.423$ & 0.005 \\
\hline
\end{tabular}

1,465 can only be derived from ristocetin by the combined loss of two hexoses, one rhamnose and one arabinose $(i=602)$ which corresponds to the composition of the B-ring tetrasaccharide (Figs. 1 and 2).

Carbohydrate composition data were obtained in a similar manner for all glycopeptides analyzed (Table 2). Fragment ions observed in the FAB mass spectrum of aridicin A (Fig. 3) indicate the presence of two terminal sugar residues: a hexose and a novel amino sugar with an incremental mass of 329 daltons (apparent $M_{r}=347$ ). These two sugars fully account for the observed mass difference between aridicin $\mathrm{A}$ and its aglycone ( $\mathrm{M}+\mathrm{H}=1,296$, Table 3$)$ and therefore are the only sugars present. As a simple means of confirming these assignments a sample of aridicin $\mathrm{A}$ was subjected to mild acid hydrolysis ${ }^{8)}$ and a FAB mass spectrum obtained on the hydrolysate without separating the individual components. Intense peaks corresponding to the $(\mathrm{M}+\mathrm{H})^{+}$ions of the two pseudoaglycones $(\mathrm{m} / z$ 1,625 and 1,458$)$, the aglycone $(m / z 1,296)$, mannose $(m / z 181)$ and the amino sugar $(m / z 348)$ are observed. Structural as well as molecular weight information is present in the FAB mass spectrum of the hydrolysate. For example, an intense peak at $m / z 172$ (elemental composition $=\mathrm{C}_{10} \mathrm{H}_{22} \mathrm{NO}$ ), an apparent fragment of the amino sugar (elemental composition $=\mathrm{C}_{10} \mathrm{H}_{30} \mathrm{NO}_{7}$ ), suggests the presence of an decanoyl substituent in this residue.

In the FAB mass spectra of aridicins $\mathrm{B}$ and $\mathrm{C}$ molecular weight-related ions and fragment ions containing the amino sugar are shifted upwards in mass by 14 and 28 mass units respectively (Table 3 ) 
Fig. 4. Theoretical isotope cluster patterns for the $(\mathrm{M}+\mathrm{H})^{+}$region of a typical glycopeptide of molecular weight 1,786 which contains from one (a) to five (e) atoms of $\mathrm{Cl}$.

a

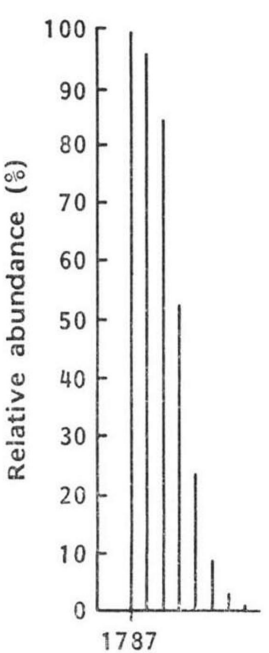

b

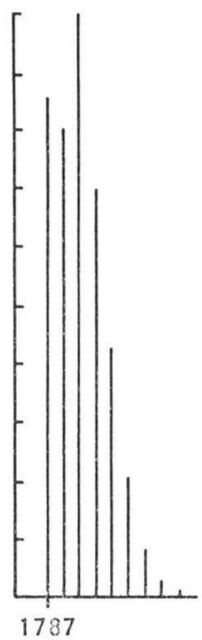

C

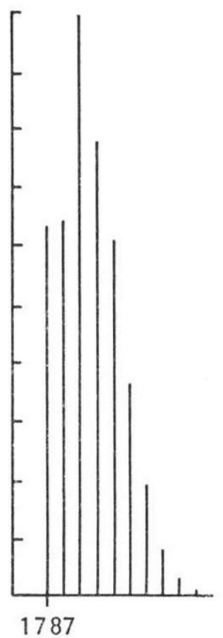

d

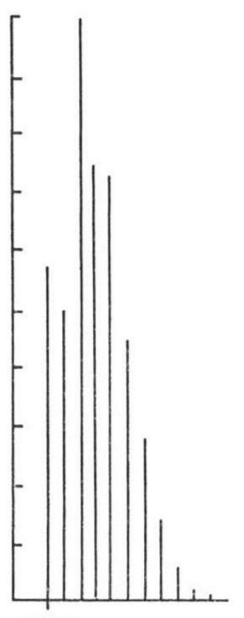

1787 e

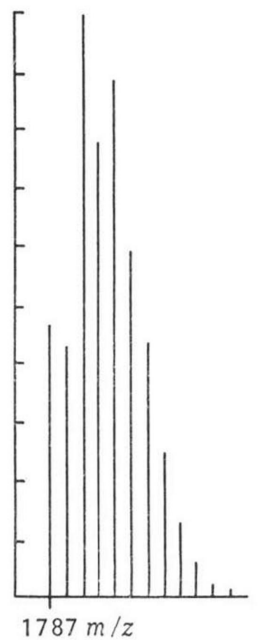

indicating the presence of structural homologs of the amino sugar which differ in the chain length of an alkyl substituent. Subsequently, the three amino sugars have been identified by GCMS and NMR as 2-deoxy-2-(alkylamido)-D-glucuronic acids, where the alkyl substituents are $\mathrm{C}_{9} \mathrm{H}_{19}, \mathrm{C}_{10} \mathrm{H}_{21}$ and $\mathrm{C}_{11} \mathrm{H}_{23}$, respectively ${ }^{8)}$.

In certain cases, limited carbohydrate sequence information could be obtained from the FAB mass spectra. For example, losses of actinosamine, acosamine and hexose from the $(\mathrm{M}+\mathrm{H})^{+}$of actinoidin $\mathrm{A}$, indicate that these residues are located at terminal (versus internal) locations. The remaining hexose moiety (Table 2) could be located at either a terminal position or within a disaccharide unit. Observation of an intense fragment corresponding to $\left[\mathrm{MH}-\left(i_{\text {acosamine }}+2\left(i_{\text {hexose }}\right)\right)+\mathrm{H}\right]^{+}$in the FAB mass spectrum suggests that the remaining hexose is present in an acosamine-hexose disaccharide. The absence of an $\left[\mathrm{MH}-2\left(i_{\text {hexose }}\right)+\mathrm{H}\right]^{+}$ion further supports an internal location for the second hexose residue.

The peaks in the molecular ion region of the aridicins were sufficiently intense to enable determinations of the accurate masses of these novel glycopeptides by high resolution FABMS (Table 3). The protonated molecular ions of aridicins A, B and C and the aglycone of aridicin A were peak matched at a resolution of 10,000 against a co-introduced oligopeptide of known structure and a molecular weight of $1,151.538$. The values obtained (Table 3 ) were in excellent agreement ( \pm 5 millimass units) with those calculated from the putative compositions.

The accuracy of the peak match method for compounds with molecular weights approaching 2,000 daltons is approximately \pm 10 millimass units. Although the theoretical number of elemental compositions that fall within this window unit of the determined value at $m / z 2,000$ is quite large, other readily available analytical data such as amino acid and carbohydrate composition, elemental analysis and spectroscopic data can be used to provide reasonable upper and lower limits on the numbers of each element that are present. The data can be used to narrow the possible elemental compositions to a relatively small number. Using this approach, the following limits were imposed for aridicin A: 70 $86 \mathrm{C}, 70 \sim 90 \mathrm{H}, 6 \sim 10 \mathrm{~N}, 25 \sim 35 \mathrm{O}$ and $1 \sim 5 \mathrm{Cl}$. The number of compositions that now must be con- 
Fig. 5. Theoretical a versus observed $\mathbf{b}$ isotope cluster patterns for the $(\mathrm{M}+\mathrm{H})^{+}$region of aridicin $\mathrm{A}$; $(\mathrm{M}+\mathrm{H})^{+}=1,787.397, \mathrm{C}_{81} \mathrm{H}_{83} \mathrm{~N}_{8} \mathrm{O}_{30} \mathrm{Cl}_{4}$.

a

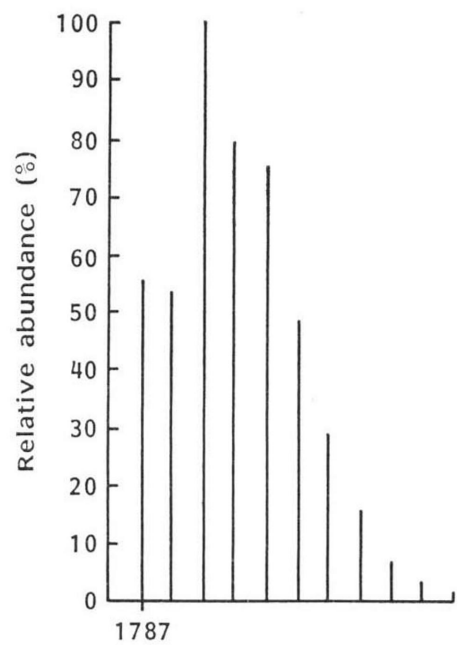

b

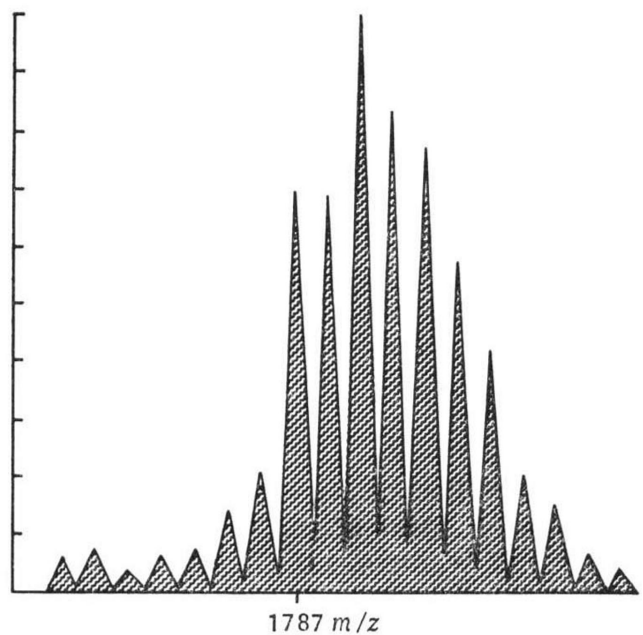

Table 4. Elemental compositions for aridicin A indicated by the accurate mass determination*.

\begin{tabular}{llrllc}
\hline $\mathrm{C}$ & $\mathrm{H}$ & $\mathrm{N}$ & $\mathrm{O}$ & ${ }^{35} \mathrm{Cl}$ & $\mathrm{MH}_{\text {caled }}-\mathrm{MH}_{\text {measured }}$ \\
\hline 83 & 79 & 10 & 27 & 4 & -0.007 \\
86 & 83 & 6 & 28 & 4 & 0.007 \\
81 & 83 & 8 & 30 & $4^{\mathrm{a}}$ & 0.003 \\
82 & 83 & 6 & 31 & 4 & -0.008 \\
76 & 83 & 10 & 32 & 4 & -0.001 \\
74 & 87 & 8 & 35 & 4 & 0.009 \\
\hline
\end{tabular}

*The number of chlorine atoms was limited to exactly four on the bsis of the observed isotope cluster pattern of the $(\mathrm{M}+\mathrm{H})^{+}$region. The range of the remaining elements was limited by other analytical data (see text).

a Established composition of aridicin A. sidered has been reduced from over several hundred to twenty-five. The number may be further reduced by comparing the observed isotope distribution for the molecular ion cluster with the calculated theoretical isotope distributions of all potential compositions $^{\theta)}$. Compositions containing the same number of $\mathrm{Cl}$ atoms produce isotope distributions that, within the element limits described above, are not clearly distinguishable from each other (data not shown). However, the isotope distributions produced by compositions with different numbers of $\mathrm{Cl}$ atoms are distinctly different (Fig. 4) because the high natural abundance of the heavy isotope of $\mathrm{Cl}\left({ }^{35} \mathrm{Cl}=77.27 \%,{ }^{37} \mathrm{Cl}=\right.$ $24.23 \%$ ). Thus, compositions containing one to five $\mathrm{Cl}$ atoms may be readily distinguished. The observed isotope pattern of the molecular ion region of aridicin A matches most closely a four $\mathrm{Cl}$ pattern (Fig 5). In addition, the fragment due to the loss of $\mathrm{Cl}$ has the pattern expected for the glycopeptide containing three $\mathrm{Cl}$ atoms, which further substantiates the number of $\mathrm{Cl}$ atoms in the intact molecule (data not shown). This conclusion now reduces the number of possible elemental compositions from 25 to 6 (Table 4).

The methods described above should only be applied when the molecular ion cluster can be observed with good signal-to-noise ratio and reliable ion statistics. Caution is required because chemical noise arising from the liquid matrix is present in all FAB mass spectra throughout the mass range. Weak sample-related signals may be enhanced by computer summing of the raw digitized data. However even when the ion statistics are good the observed isotope cluster patterns will not precisely 
match the theoretical pattern. This is principally due to minor contributions from $\mathrm{M}^{+\cdot},(\mathrm{M}-\mathrm{H})^{+}$, $(\mathrm{M}-2 \mathrm{H})^{+\cdot}$ as well as $(\mathrm{M}+2 \mathrm{H})^{+\cdot}$ and $(\mathrm{M}+3 \mathrm{H})^{+}$.

These results indicate that FABMS is a very powerful tool for the structural characterization of glycopeptide antibiotics. The data presented herein demonstrate the utility of the method in providing valuable structural information including molecular weight, elemental composition and carbohydrate composition for small amounts of material. These virtues dictate that FABMS be one of the first analytical techniques implemented in the structural characterization of an unknown glycopeptide.

\section{Acknowledgments}

The authors would like to thank R. Sitrin, G. Chan and G. Udowenko of Smith Kline \& French Laboratories for valuable discussions and for supplying purified samples of aridicins $\mathrm{A}, \mathrm{B}$ and $\mathrm{C}$.

\section{References}

1) Barber, M.; R. S. Bordoli, G. R. Elliott, R. D. Sedgwick \& A. N. Tyler: Fast atom bombardment mass spectrometry. Anal. Chem. 54: 645A 657A, 1982

2) Sitrin, R. D.; G. W. Chan, J. J. Dingerdissen, W. Holl, J. R. E. Hoover, J. R. Valenta, L. Webb \& K. M. SnAder: Aridicins, novel glycopeptide antibiotics. II. Isolation and characterization. J. Antibiotics 38: $561 \sim 571,1985$

3) Wiliams, D. H.; V. Rajananda, M. P. Williamson \& G. Bojesen: The vancomycin and ristocetin group of antibiotics. Top. Antibiot. Chem. 5: 119 158, 1980

4) Barber, M.; R. S. Bordoli, R. D. Sedgwick, A. N. Tyler \& B. W. Bycroft: A new method applied to some intractable antibiotics. In Applications of Mass Spectrometry in Biochemistry and Medicine. Ed., A. Frigerio, Anal. Chem. Symposium Series (Recent Developments in Mass Spec., Biochem., Medicine and Environmental Research, 8) Vol. 12, pp. 129 133, 1983

5) Hunt, A. H.: Structure of the pseudoaglycon of A35512B. J. Am. Chem. Soc. 105: 4463 4468, 1983

6) Roberts, G. D.; S. Rottschaefer \& W. Johnson: "Continuum Acquisition": A computer technique to evaluate high mass peaks in the spectrum. Abstract 31st Ann. Con. Mass Spectrum Allied Topics, pp. $165 \sim 166,1983$

7) Roberts, G.; S. Rottschaefer, R. Sitrin \& P. JefFs: Fast atom bombardment mass spectrometric carbohydrate analysis of glycopeptide antibiotics. Abstract 32nd Ann. Conf. Mass Spectrum Allied Topics, pp. $341 \sim 342,1984$

8) Jeffs, P. W.; G. Chan, R. Sitrin, N. Holder \& C. DeBrosse: The structure of the glycolipid components of the aridicin antibiotic complex. J. Org. Chem. 50:1726 1731, 1985

9) Yergey, J.; D. Heller, G. Hansen, R. J. Cotter \& C. Fenselau: Isotopic distributions in mass spectra of large molecules. Anal. Chem. 55: 353 359, 1983

10) Barna, J. C. J.; D. H. Williams, D. Stone, J. M. Leung, T.-W. Christina \& D. M. Doddrell: Structure elucidation of the teicoplanin antibiotics. J. Am. Chem. Soc. 106: 4895 4902, 1984

11) Hunt, A. H.; R. M. Molloy, J. L. Occolowitz, G. G. Marconi \& M. Debono: Structure of the major glycopeptide of the teicoplanin complex. J. Am. Chem. Soc. 106: 4891 4895, 1984 